\title{
Heavy Metals Uptake Levels in Crop Fields of Two S.A.A.R.C. Countries and Their Health Risk Assessments - A Review
}

\author{
Z. R. Sultan*, M. S. Nasar, M. Ahmed, M. Saqib, Y. Ehsan, M. H. Tariq, A. Mahmood \\ School of Natural Sciences, National University of Sciences and Technology, Islamabad, Pakistan
}

*Corresponding Author's Email: dr.azhar@sns.nust.edu.pk

\begin{abstract}
This review article highlights the Heavy metals contamination and its uptake in the crops of the S.A.A.R.C. region. The article discusses several reports about the heavy metal toxicity and its spreading in the fields and ultimately taken up by the crops, and transference from the anthroposphere to the humans and animals in the subcontinent or the S.A.A.R.C. regions, namely Pakistan and Bangladesh. It was observed from the reports that most of the heavy metals belong to the transition metals like Nickel (Ni), Cadmium (Cd), Cobalt (Co), Zinc ( $\mathrm{Zn})$, Manganese (Mn), Mercury ( $\mathrm{Hg})$, and Lead ( $\mathrm{Pb}$ ), etc. Another salient consideration is how these heavy metals end up in the water and soil and the various anthropogenic sources of these heavy metallic contaminations. The amount in the contaminated and uncontaminated regions was compared experimentally with the allowed amounts in soils of fields and water bodies. It was made according to the local standards and parameters set by the different scientific communities locally and globally (WHO). Different sampling methods were adopted, and the heavy metal uptake and their amounts in the various plant bodies were determined. At the same time, comparisons between the affected and non-affected areas were conducted, and conclusions were drawn from the analysis.
\end{abstract}

Keywords: S.A.A.R.C. regions, heavy metal, Crops, WHO

\section{INTRODUCTION}

Heavy metal pollution is increasing exponentially day by day, and the world is now in its evil claws, in many ways it is disturbing the environment and ultimately imposing severe health problems to the human. In developing countries like India and Pakistan, where the population is very high, such issues are rising drastically due to rapid urbanization, industrialization, and changes in land use[1]. Rapid globalization and industrialization have diversified these pollutants exponentially with hundreds and thousands of anthropogenic sources. It has become a global issue due to its ever-evolving various problems regarding food security and its inevitable association with human health[2-4]. Some of the heavy metals (i.e., $\mathrm{Mg}, \mathrm{Fe}, \mathrm{Cu}$, $\mathrm{Zn}, \mathrm{Mo}$, and $\mathrm{Se}$ ) are essential and needed by the human body in specific amounts for the proper function of the human body and are indistinguishably linked with chemical and biological processes occurring in the cells[5].

Nickel is an integral element of urease, required for the proper functioning of the metabolic processes. It will cause human health risks at excessive levels [5, 6]. But many of them are not needed by the human body and are classified as non-essential (i.e., $\mathrm{As}, \mathrm{Ni}, \mathrm{Pb}, \mathrm{Cd}$, and $\mathrm{Hg}$ ). These hazardous heavy metals have many adverse health effects and are harmful in many ways. Hence, these heavy metals are included in the top 20 list of dangerous substances by the United States Environmental Protection Agency and the Agency for Toxic Substances and Disease Registry (A.T.S.D.R.)[3, 7-11]. Consequently, within the environment, soil-crop fields/vegetable systems present a classic example of abiotic-biotic interactions.

The soil is rudimental and basal nutrition for the crop fields, and the point and non-point sources are surpassingly contaminating it. Point sources are chlor-alkali chemical processes (i.e., goldmines, textiles, smelting, leather, textiles, and electroplating). On the other hand, non-point sources are agricultural runoff, sediment/soil erosion, and open freight storage. The uptake level of heavy metals such as $\mathrm{Cu}, \mathrm{Zn}, \mathrm{Mn}, \mathrm{Pb}$, and $\mathrm{Cd}$ is higher in the greenhouse crops than in the open field crops, conceivably due to the lower luminance[12]. To formulate productive remediation techniques and processes, one must understand how these heavy metals transfer from soil into the crops and ultimately into the human body. In search of this goal, this review article will apprise the diverse sources of heavy metal contaminations in the soil, their uptake levels in the various crop fields of the Pakistan \& Bangladesh region, and their human health implications associated with dietary intake of these contaminated crops.

Most importantly, this review gives an overview of the geographical pattern of these heavy metal sources in the Pakistan \& Bangladesh regions and which specific heavy metals are accumulating and affecting these areas and the people residing in them. It also discusses the uptake level of these metals in the crop fields in the various areas of the Pakistan \& Bangladesh region and their anthropogenic factors. In the end, the remedial approaches, strategies, and future will be discussed to help appropriately to manage the contamination of these dangerous metals so that a balance could be maintained. All these management approaches, strategies, methods, and plans are inevitably connected with human wellbeing by minimizing or suppressing soil contamination by these dangerous metals and their transfer into the food chain through the crop fields. 


\subsection{HEAVY METAL UPTAKE LEVELS IN CROPS OF PAKISTAN}

\subsubsection{Heavy metals uptake in vegetable crops in Sargodha city Pakistan}

Consequent human disclosure hazards were resolute at Sahiwal and Shahpur within the Sargodha city of Pakistan, where dirty water is used for watering vegetable grown-ups. The study confirmed metal stages in the soil tasters were comparatively below the respective extreme permissible bounds of many examined metals. The meditation in vegetable was $\mathrm{Mn}>\mathrm{Fe}>\mathrm{Cr}>\mathrm{Mo}>\mathrm{Pb}>\mathrm{Cd}$. In both areas, the transmission feature is from 0.01 to 71.295 , with Cr has a large transmission feature.

\subsubsection{Resources and Approaches}

The work region was in the Sargodha area. Sargodha is an agrarian place, reality most significant citrus developing region on the planet. The examples of Cucurbita maxima (eatable part) and rhizosphere earth were gathered from Sahiwal and Shahpur.

\subsubsection{Test assortment}

A compound earth model of just about one kilogram was gathered below the vegetable. The composite soil is comprised of five sub-models. The mud was uncovered to twenty-centimeter profundity soil models dehydrated in air and afterward dried at seventy-two degrees in a broiler for three sequential existences[13]. The dry soil was pummeled and squashed into dust structure by utilizing a processor, sifted, and afterward gathered in malleable packs. Six repeats of the vegetable (eatable part) were gathered. Vegetables were washed once with purified water to eliminate air-conceived toxins. Palatable parts were censored into tiny bits with a blade and dried in daylight to eliminate dampness and afterward positioned in a stove at seventy-two-degree for two days. Dried examples were crushed to go through a 1milli meter lattice strainer and put away in fresh malleable sacks earlier examination.

\subsubsection{Breakdown of earth and vegetable samples}

The earth model was processed by the rainy absorption method. One gram earth model was engaged in a bottle and then put to eight $\mathrm{mL}$ of hydrogen peroxide and four $\mathrm{mL}$ of sulphuric acid. Models were put for 30 minutes in an ingestion cavity at a suitable temperature. Subsequently, the ingestion was finished, two $\mathrm{mL}$ of hydrogen peroxide was added to each bottle. Altogether samples were heated till the models turn color to colorless. Later selecting the condensations, the last volume of each model was elevated to fifty $\mathrm{mL}$ and then kept in plastic flasks until examination. 1 gram dry sample was occupied in a bottle, and $4 \mathrm{~mL}$ of hydrogen peroxide and $2 \mathrm{~mL}$ of Sulphuric acid were put into it.

\subsubsection{Metals verification}

The concentration of metals in vegetables and earth samples was conducted using submicroscopic fascination spectrophotometer. The standard solutions of $\mathrm{Cr}, \mathrm{Mn}, \mathrm{Fe}, \mathrm{Mo}, \mathrm{Pb}$, and $\mathrm{Cd}$ were used as a standard for the exact values.

\subsubsection{Geometric study}

ANOVA was applied. The connection among earth and vegetal per esteem near every metallic is operated available. A consequence of proceeds is verified at possibility stages of $0.001,0.01$, and 0.05 .

\subsubsection{Transmission feature}

ITo determine the metal gathering from earth to vegetal, transmission feature was calculated[14], TF=[M]vegetable $/[\mathrm{M}]$ soil. Where $[\mathrm{M}]$ herbal is the concentration of metal in taters $(\mathrm{mg} / \mathrm{Kg})$ and $[\mathrm{M}]$ soil is the concentration of metal in the earth $(\mathrm{mg} / \mathrm{Kg})$.

\subsubsection{Outcomes}

Convergence of substantial metal of earth tests, the groupings of substantial metal went between 0.174 to $0.257 \mathrm{mg} / \mathrm{Kg}$ for Chromium, 18.83 to 21.62 for Manganese, 24.23 to 29.44 for iron, 11.84 to 14.09 for Molybdenum, 22.33 to 23.16 for lead, and 16.89 to 17.89 for $\mathrm{Cd}$ individually. Complete grouping of heavy metal identified in the dirty water with wastewater at the two destinations was less the utmost reasonable level apart from Cd U.S.E.P.A. Standards. The mean estimations of Chromium in maxima went from 12.40 to $13.52 \mathrm{mg} / \mathrm{Kg}$ at the two locales. The outcomes indicated that the capacities proverb during the current investigation were lower than as far as possible $(50 \mathrm{mg} / \mathrm{kg})$ revealed by the WHO $(1993,1996)$. 


\subsubsection{Metal transmission}

The standard exchange feature for Chromium, Manganese, iron, Molybdenum, Lead, and Cadmium at the two locales compared. Interchange feature for vegetal to earth framework went since 0.013 to 71.29 . The entreaty for move factor for metals like Chromium 71.29 > Manganese $2.84>$ iron 1.74 > Molybdenum $00.67>$ lead 00.07> Cadmium 00.02 at Sahiwal and Chromium 52.60 Manganese $02.07>$ iron $01.60>$ Molybdenum $00.54>$ lead $00.09>$ Cadmium 00.01 at Shahpur, individually (Fig. $1 \& 2$ ).

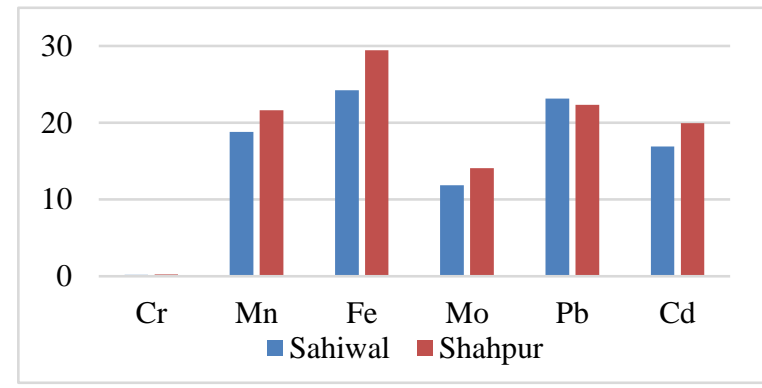

Fig. 1: Conc (ppm) of some heavy metals in Cucurbita maxima

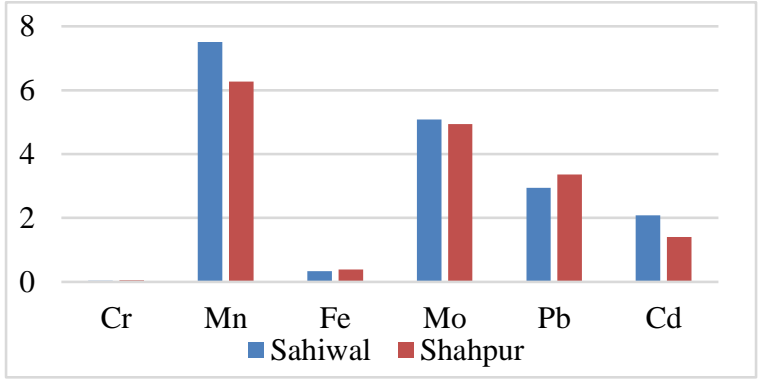

Fig. 2. Health risk intake of heavy metals via intake of Cucurbita maxima

\subsubsection{Heavy Metal Intake via Intake of Foodstuff in Multan City Pakistan}

The expression "substantial metals" relates to a slightly metal component to a generally large thickness and is harmful even at less focus. Wastewater contains characteristic heavy metals like $\mathrm{Zn}, \mathrm{Cd}, \mathrm{Cr}, \mathrm{Pb}, \mathrm{Cu}, \mathrm{Mn}$, etc. These toxic metals may accumulate in soil and vegetables. Heavy metals get consolidated into plants through roots. In a wet climate, plants' entire body is accessible to these particles. Leaves straightforwardly adsorb heavy metals because of metal particles consolidated on their foliar surfaces. The $\mathrm{pH}$ of soil decides the degree of heavy metals in the horticulture world.

\subsubsection{Testing}

Testing of water, roots, stem, leaves, and products of L. esculentum was gathered from three distinct areas of Multan locale as given: W1: flooded with sewerage water (area: Raheelpur); W2: flooded with waterway water (area: Nawabsadiqhussain); W3: flooded with tube well water arranged close to modern waste unloading (Muradwala). Water tests were gathered in reagent containers, and plants were uncovered from soil and gathered in polythene packs[15].

\subsubsection{Test treatment}

Plants were separated into roots, leaves, stems, and products of the soil dried at 1100C. $2 \mathrm{~g}$ of each sample was processed with $5 \mathrm{~mL}$ conc. Nitric acid. Tests were kept on a hot plate with a striking stirrer. These examples were examined utilizing pre-treated channel paper whatman 42 in $100 \mathrm{~mL}$ graduated chamber. The final volume was made $50 \mathrm{ml}$ for each example with deionized water. Water tests were straightforwardly oppressed for investigation.

\subsubsection{Test investigation}

Tests of water and plant parts were exposed to nuclear assimilation spectrometer to examine metals zinc, calcium, and magnesium. Standard arrangements of Zinc, calcium, and magnesium were readied utilizing Zinc acetic acid derivation $\left(\mathrm{C}_{4} \mathrm{H}_{6} \mathrm{Zn} \cdot 2 \mathrm{H}_{2} \mathrm{O}\right.$ ), calcium chloride (Model A-1800 for the $\left.\mathrm{CaCl}_{2}\right)$, and $\mathrm{Mg}\left(\mathrm{NO}_{3}\right)_{2} \cdot 6 \mathrm{H}_{2} \mathrm{O}$ in water. Instrument setting and operational conditions were set as per the maker's particulars.

\subsubsection{Factual examination}

Data was examined utilizing IBM SPSS, Statistics rendition 23. Correlation of the mean qualities between bunches was performed utilizing One-way ANOVA. P esteem $<0.05$ was considered measurably critical. Regular admission of metals (D.I.M.):

Day-by-day admission of metals is the inferred assessment of substantial metals taken by the human population in their dayby-day diet and was determined by utilizing the following formula[16].

$$
\mathrm{DIM}=\mathrm{C}_{\text {metal }} \times \mathrm{C}_{\text {factor }} \times \mathrm{D}_{\text {food }} \quad \text { Consumption/Beverage weight }
$$

The day-by-day ingestion rate for chosen M.F.C.s determined for L. esculentum was $26.0 \mathrm{~g} / \mathrm{individual} / \mathrm{day}$. The regular vegetal charge was registered by coordinating a survey where around 200 people of 55.2 kilograms were mentioned their step-by-step charge of clear taters shape inspecting places. 


\subsubsection{Health Risk Index (H.R.I.)}

The health hazard list (H.R.I.) esteem was inspected by utilizing the following equation [8], including D.I.M. and reference oral portion (RfD) for single poisonous substantial

metal.

$$
\mathrm{HRI}=\mathrm{DIM} / \mathrm{RfD}[17\rceil
$$

If H.R.I.> 1, at that point, the uncovered public warrants further examination for any clinical issues. Human danger evaluation for $\lceil 12\rceil \mathrm{Zn}, \mathrm{Ca}, \mathrm{Mg}$ was determined by the given condition. $\mathrm{R}_{\mathrm{f}} \mathrm{D}$ esteems for Chromium, Nickle, Copper, Lead, Cadmium, Manganese and Zinc is 1.5, 0.02, 0.04, 0.004, 0.001, 0.033 and $0.30 \mathrm{mg} / \mathrm{Kg}$ per day[18].

\subsubsection{Outcomes}

Collected information indicated that the particular bioavailability of Zinc in roots tested from W1, W2, and W3 was 13.7 $\mathrm{mg} / \mathrm{Kg}, 2.33 \mathrm{mg} / \mathrm{Kg}$, and $31.69 \mathrm{mg} / \mathrm{Kg}$, respectively. If there should arise an occurrence of stem inspected from W1, W2, and W3 individually, the bioavailability of Zinc was $11.11 \mathrm{mg} / \mathrm{Kg}, 0.98 \mathrm{mg} / \mathrm{Kg}$, and $0.61 \mathrm{mg} / \mathrm{Kg}$, respectively [15].

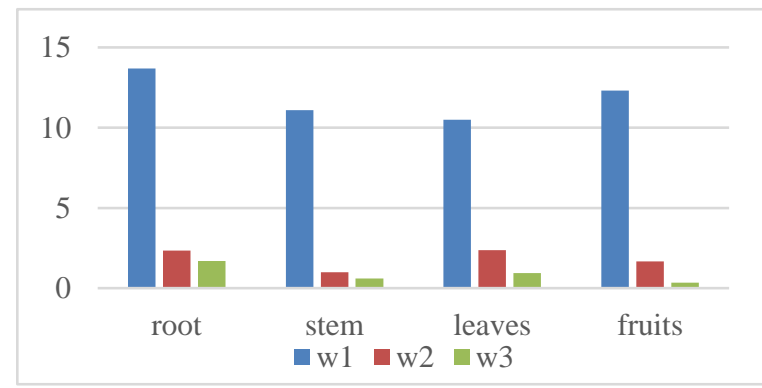

Fig. 3: Zinc conc. (ppm) in L. esculentum at different water quality levels

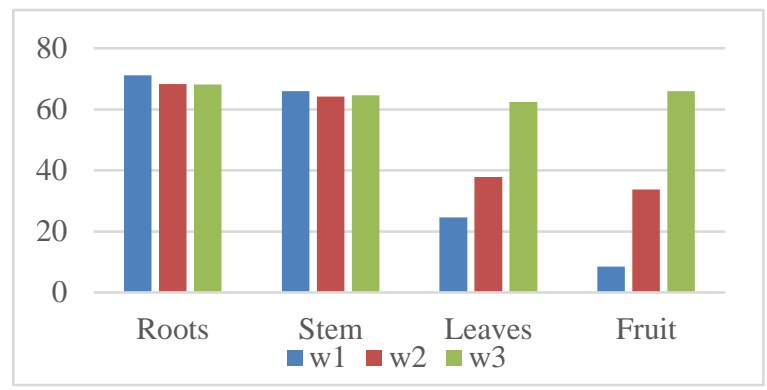

Fig. 4: Calcium conc. (ppm) in L.esculentum at different water quality levels

Separate phytoavailablity division of Zinc in leaves from W1, W2, and W3 was $10.5 \mathrm{mg} / \mathrm{Kg}, 2.37 \mathrm{mg} / \mathrm{Kg}$, and $0.94 \mathrm{mg} / \mathrm{kg}$, respectively, while in the event of organic product, accessibility of Zinc was $12.3 \mathrm{mg} / \mathrm{kg}, 1.67 \mathrm{mg} / \mathrm{Kg}$, and $0.35 \mathrm{mg} / \mathrm{Kg}$ for W1, W2, and W3 individually[15] (Figure 3-5).

\subsection{HEAVY METALS UPTAKE LEVELS IN CROP FIELDS OF BANGLADESH}

Bangladesh is one of the highly populated nations globally, with 1278 individuals for every square kilometer. Cases give an account of increased exposure to harmful heavy metals and metalloid lately in Bangladesh. In Bangladesh, groundwater arsenic tainting has become a significant general medical issue[19]. Rapid industrialization, urbanization, and different anthropological exercises have driven the wide scattering of Cadmium, lead, and chromium in the environment[19].

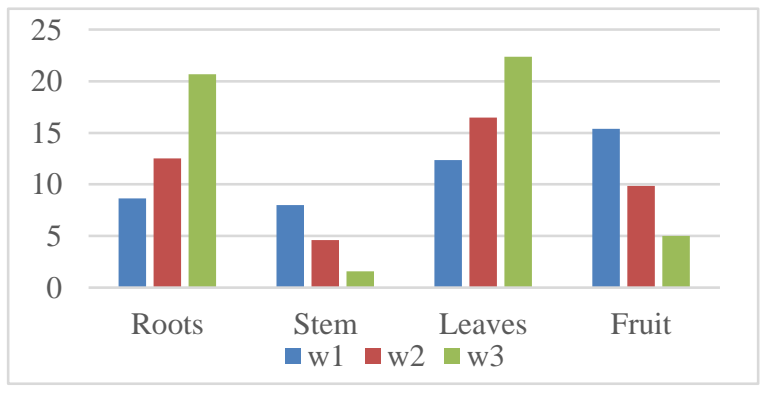

Figure 5. Magnesium conc. (ppm) in L. esculentum at different water quality levels

Mechanical effluents and sewage fall into running stream water in frequent perceptions. Fish species from contaminated waterways additionally contain an elevated concentration of heavy metals. Soil close to the mechanical zones of the enormous urban areas in Bangladesh, such as Dhaka, Gazipur, Chittagong, and Bogra, showed abundant metals and metalloids[19]. High traffic loads are additionally answerable for high substantial metal and metalloid contamination in water and soil[19]. In the interim, agrarian items from contaminated soil are often found to contain high convergences of heavy metals and metalloids, affecting human wellbeing significantly. 
Pakistan Journal of Chemistry 2021

Bangladesh creates more than 90 sorts of vegetables and 60 sorts of fruits[19]. Ecological contamination and the nature of the dirt straightforwardly influence the heavy metal and metalloid substance in nourishments. Constituents like pesticides and manures containing substantial metals and metalloids are both significant wellsprings of heavy metals and metalloids in nourishments. Some metals are fundamental in plant nourishment; nevertheless, the overabundance of heavy metals and metalloids can aggregate in different edible and non-eatable pieces of plants. Essentially, green vegetables are more obligated to substantial metal and metalloid dissent because of their fast development and direct exchange of metals and metalloids to the green parts[19].

A water system with arsenic-debased groundwater is the essential driver of food arsenic tainting in Bangladesh. Natural arsenic in nourishments is viewed as less spiteful. Arsenic-containing field crops may contain an enormous bit of inorganic arsenic. Besides drinking water, food arsenic introduction was likewise discovered as a significant pathway liable for As harming[4-6].

\subsubsection{Crops nearby Industrial Areas}

Industrial or metropolitan wastewater is generally utilized for the water system of fields because of its simple directness, removal, and shortage of new water. Water system with wastewater is known to contribute essentially to the heavy metals substance of soil. Wastewater may contain different weighty metals, including Zinc ( $\mathrm{Zn})$, copper $(\mathrm{Cu})$, lead $(\mathrm{Pb})$, arsenic (As), nickel (Ni), chromium (Cr), and cadmium (Cd), contingent on the sort of exercises related with it. The consistent water system of rural land with sewage and modern wastewater may cause substantial metal collection in the dirt and vegetables[59].

\subsection{2. $\quad$ Sampling and analysis}

Different investigations demonstrated[10-18] that plants cultivated nearer to modern industrial zones accumulate more substantial metals and metalloids than non-industrial regions. For this literature from different field crops, especially vegetables, were taken into consideration as model sampling and data collection of heavy metal uptake level in the famous Industrial areas located in Chittagong, Bangladesh, Dhaka Export Processing Zone (D.E.P.Z.), and Hazaribagh leather industry located in Dhaka, capital of Bangladesh and their surrounding areas. Spinach, Eggplant, Chili, tomato, lady's finger, cabbage, and bottle gourd are primarily grown in the surrounding areas of the regions mentioned above[16-18].

\subsubsection{Crops nearby high traffic areas}

The release of heavy metals from traffic exercises is a significant contamination source to the side of the road field environments. The plants on the roadside always suffer from the accumulation of $\mathrm{Pb}$ accumulation and sulfate and sulpher gases[11].

\subsubsection{Sampling and analysis}

Vegetables grown in high traffic areas were also found to contain higher concentrations of heavy metals and metalloids[19]. The literature revealed heavy metal uptake levels in different field crops, especially vegetables grown near the famous roadside of Joydebpur in the region of Ghazipur, Bangladesh, and Dhaka Export Processing Zone (D.E.P.Z.) contain heavy metal. Though D.E.P.Z. can be included in the contamination of soil by the irrigation with contaminated sewage water, here it is taken into account for the fuel used by the vehicles, transport cargos, etc. The crops include eggplant, chili, tomato, lady's finger, and cabbage from the areas near D.E.P.Z. Whereas pumpkins and bottle gourd from the regions near the roadside of Joydebpur, Ghazipur, Bangladesh.

\subsubsection{Crops near rivers}

Most zones of Bangladesh are windy areas that are wealthy in waterways. The stream frameworks and precipitation significantly route the territorial and cross-local dispersal of toxins, especially heavy metals and metalloids. Water systems with contaminated river water may significantly influence metal and metalloid in vegetables[11-14].

\subsubsection{2. $\quad$ Crops nearby Industrial Areas}

It was reported that heavy metals like $\mathrm{Cd}, \mathrm{Pb}$, and $\mathrm{Cr}$ were common in vegetables grown near industrial Zone, heavy traffic road zone, and rivers side where wastewater discharge. Soil close to the mechanical zones of the enormous urban areas in Bangladesh, Dhaka, Gazipur, Chittagong, and Bogra, showed an abundance of substantial metals and metalloids[19]. High traffic loads are additionally answerable for high metal and metalloid contamination in water and soil [19]. 


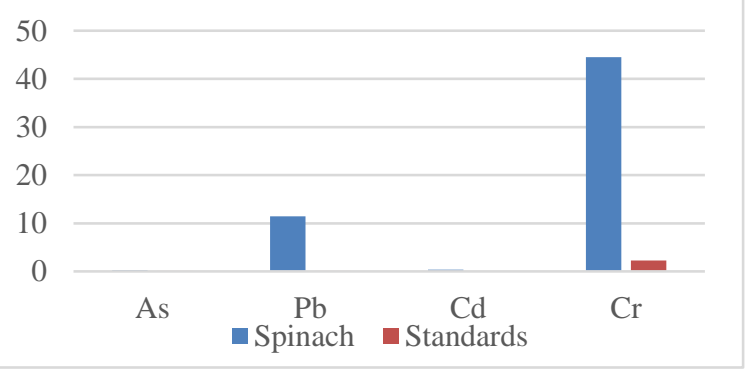

Fig. 6: Heavy metal conc. (ppm) in vegetables near Hazaribagh leather Industry

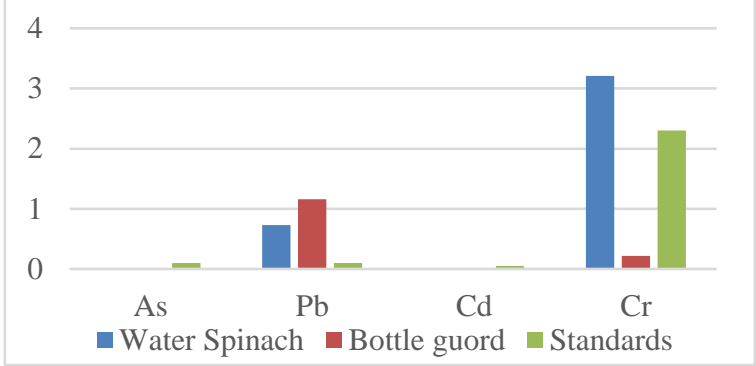

Fig. 7: Heavy metal conc. (ppm) in vegetables near Vatiary Industrial Area

It was also reported that soil containing heavy metals in certain parts of Bangladesh is greatly influenced by mining. The natural concentration of $\mathrm{Pb}$ is highly affected by coal, coal debris, and coal-terminated boilers. Modern and metropolitan effluents discharge enormous amounts of metalloid and heavy metals that are very much responsible for soil and water contamination by heavy metals. The culprits of increased heavy metals and metalloids in agricultural lands and vegetable plots of Pakshi are phosphate insecticides and manures due to their maximum utilization.

Lead (22.09 ppm), Cadmium (2.05 ppm), and Chromium (7.58 ppm) in higher fixations as compared to standards were found in the cabbage from a farming area close by D.E.P.Z. Arsenic $(0.26 \pm 0.22 \mathrm{ppm})$, lead $(44.48 \pm 4.98 \mathrm{ppm})$, Cadmium $(0.32 \pm 0.094 \mathrm{ppm})$, and Chromium $(44.48 \pm 12.59 \mathrm{ppm})$ were found in higher concentrations as compared to the standards in the spinach grown in the agricultural fields near Hazaribagh Leather Industry and different industrial areas of Dhaka. The concentrations of Chromium and lead in bottle gourd and spinach is grown near Vatiary industrial Zone of Chittagong also surpassed the standard limits (bottle guard contained $1.16 \pm 0.01 \mathrm{ppm}$ and spinach contained $3.21 \pm 0.023 \mathrm{ppm}$ ).

\subsubsection{Crops nearby high traffic areas}

Increased concentrations of heavy metal and metalloid were observed in the crops grown in the agricultural fields near main highways and roads. Lead $(4.76 \pm 1.03 \mathrm{ppm}) \&$ Cadmium $(0.2 \pm 0.02 \mathrm{ppm})$ were observed in pumpkin, and lead (1.16 $\pm 0.001 \mathrm{ppm}$ ) was discovered in bottle gourd grown in the agricultural fields that are near to the roadway in Joydevpur. These concentrations are very high as compared to their standard concentrations.

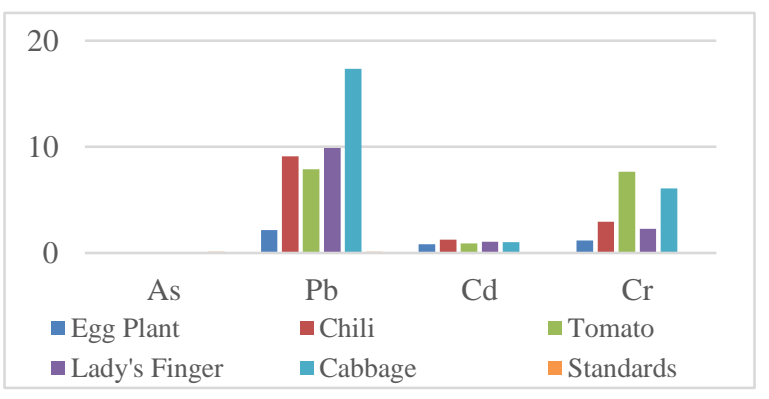

Fig. 8: Heavy metal conc. (ppm) in vegetables near Dhaka Export Processing Zone

\subsubsection{Crops near rivers}

Situated on the bank of the Buriganga River, the biggest city of Bangladesh is Dhaka. Shitalakhya, Balu, Dhaleswari, and Turag are the significant rivers found near Dhaka. Substantial metalloid and metal burden along these rivers expanded to abrupt levels from different sources in a recent couple of years; this way, in Bangladesh, these streams are known as the "Biologically Dead Rivers." Groupings of Lead, Cadmium, and Chromium higher than the Safe limits are found in the slit of Buriganga River. Lead (0.073-0.1ppm) and Chromium (0.039-0.061 ppm) in higher amounts in light of the substantial industrialization are contained by two sides of the Turag River. Cadmium $(0.8 \mathrm{mg} / \mathrm{kg})$ and Chromium $(178 \mathrm{mg} / \mathrm{kg})$ in abundance concentrations are also contained by this stream's residue. Water systems considerably influence by metalloid and metal convergences of vegetables with tainted river water. The Turag River is encompassed by red amaranth from rural land extensively contaminated by Lead $(1.99 \pm 0.44 \mathrm{mg} / \mathrm{kg})$ and Cadmium $(0.84 \pm 0.17 \mathrm{mg} / \mathrm{kg})$. The Puthe Shitalakhya River is encompassed by purple amaranth from horticultural land contaminated by lead and Cadmium. 


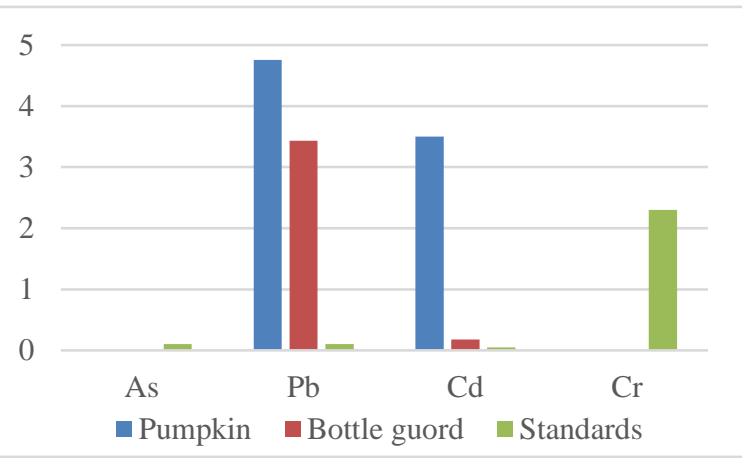

Figure 9. Heavy metal conc (ppm) in vegetables near Roadside of Joydevpur

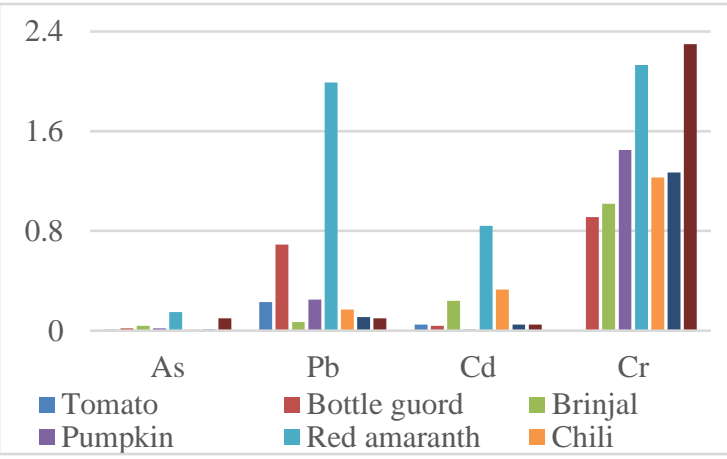

Figure 10. Heavy metal conc (ppm) in vegetables near Turag River

\subsubsection{Vegetables in markets}

Vegetables, Rice, and fish of Dhaka and Kawran Bazar contained $\mathrm{Pb}$ and $\mathrm{Cd}$ in higher fixations than safe limits. According to the investigation based on the market, tomatoes containing $\mathrm{Cd}$ are highly toxic, and mangoes had a higher amount of $\mathrm{Pb}$. The permissible level of As established by the World Health Organization and the United States Environmental Protection Agency is $10 \mathrm{ppb}$; however, in many developing countries like Bangladesh, it has been adjusted to $100 \mathrm{ppb}$ because of inadequate analytical instruments for lower arsenic concentrations.

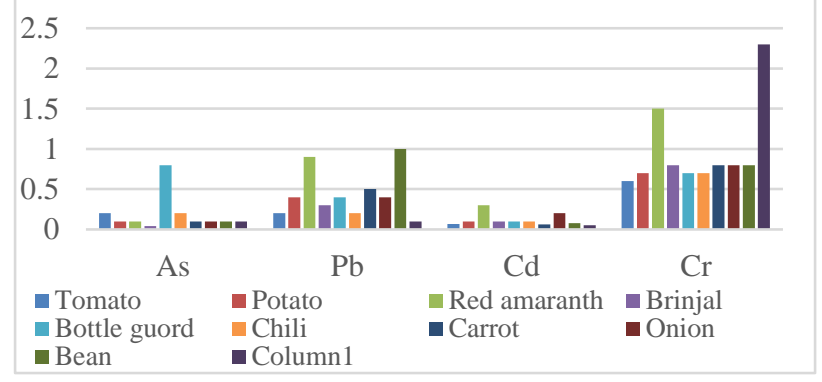

Figure 11. Heavy metal conc (ppm) in vegetables near Paira River

The same is the case for $\mathrm{Pb}, \mathrm{Cd}$, and $\mathrm{Cr}$ compared with $100 \mathrm{ppb}, 50 \mathrm{ppb}$, and $2.3 \mathrm{ppm}$, respectively. These standards are high, comparing them with the guidelines of WHO [19].

\section{CONCLUSION}

It was concluded that heavy metal contamination is a critical issue in the current era of advancement due to their improper placement in the last 50 years. The discharge of heavy metals as waste in soil and water resources results in the accumulation of the plants, especially in vegetable crops. It is the primary transfer source of heavy metals in the human results in several severe diseases like cancer, vision impairment, diabetes, hypertension, depression, and in some cases, may cause death. Some prevalent diseases are kidney stones and stones in other organs like gallbladder and liver(Cu copper) stones. This article will develop general public awareness about heavy metal contaminations and scientists to develop more effective techniques to avoid heavy metal accumulation in vegetable crops.

\section{ACKNOWLEDGMENT}

The author is thankful to the library of NUST to provide a literature facility to compile this review article

\section{CONFLICT OF INTEREST}

It is declared that there is no conflict of interest among Authors.

\section{REFERENCES}

1. U. N. Habitat. Globalization and Urban Culture. (2004).

2. B. O. Clarke, S. R. Smith. Environment international, 37(1), 226-247. (2011).

3. P. K. Rai. CRC Press. (2018).

4. I. Säumel, I. Kotsyuk, M. Hölscher, C. Lenkereit, F. Weber, I. Kowarik. Environmental Pollution, 165, 124-132. (2012). 
5. H. Marschner. Academic press. (2011).

6. P. Zhuang, M.B. McBride, H. Xia, N. Li, Z. Li. Science of the total environment, 407(5), 1551-1561. (2009).

7. D. Moffett, C. Smith-Simon, Y.W. Stevens. Toxicological profile for barium and barium compounds. (2007).

8. S. Khalid, M. Shahid, N.K Niazi, B. Murtaza, I. Bibi, C. Dumat. Journal of Geochemical Exploration, 182, 247268. (2017).

9. T. Xiong, A. Austruy, A. Pierart, M. Shahid, E. Schreck, S. Mombo, C. Dumat. Journal of Environmental Sciences, 46, 16-27. (2016).

10. T. Xiong, C. Dumat, A. Pierart, M. Shahid, Y. Kang, N. Li, C. Laplanche. Environmental geochemistry and health, 38(6), 1283-1301. (2016).

11. P.K. Rai, S.S. Lee, M. Zhang, Y.F. Tsang, K.H. Kim. Environment international, 125, 365-385. (2019).

12. F. L. Li, W. Shi, Z. F. Jin, H. M. Wu, G. D. Journal of Geochemical Exploration, 173, 76-84. (2017).

13. P. A. Sanchez. Properties and Management of Soils in the Tropics. (1976).

14. Y. J. Cui, Y. G. Zhu, R. H. Zhai, D. Y. Chen, Y. Z. Huang, Y. Qiu, J.Z. Liang. Environment international, 30(6), 785-791. (2004).

15. M. Ibrahim, M. Afzaal, M. Hussain, M. Khalid, A. Hussian, Y. AzharRasul, S.Ahmed, S. Annals of Life Sciences. (2019).

16. N. S. Chary, C. T. Kamala, D. S. S. Raj, Ecotoxicology and environmental safety, 69(3), 513-524. (2008).

17. U. EPA. US Environmental Protection Agency Washington DC. EPA-922-R-02-019. (2002).

18. U. EPA. US Environmental Protection Agency. (2010).

19. M.M. Islam, M. M. Karim, X. Zheng, X. Li. International journal of environmental research and public health, 15(12), 2825. (2018). 